\title{
Targeted blockade in lethal West Nile virus encephalitis indicates a crucial role for very late antigen (VLA)-4-dependent recruitment of nitric oxide-producing macrophages
}

Daniel R Getts ${ }^{1,3}$, Rachael L Terry ${ }^{1,3}$, Meghann Teague Getts ${ }^{1,3}$, Marcus Müller ${ }^{2,3}$, Sabita Rana ${ }^{1,3}$, Celine Deffrasnes ${ }^{1,3}$, Thomas Myles Ashhurst 1,3, Jane Radford ${ }^{1,3}$, Markus Hofer ${ }^{2,3}$, Shane Thomas ${ }^{4}$, lain L Campbell ${ }^{2,3}$ and Nicholas JC King ${ }^{1,3^{*}}$

\begin{abstract}
Infiltration of Ly6C $\mathrm{C}^{\text {hi }}$ monocytes from the blood is a hallmark of viral encephalitis. In mice with lethal encephalitis caused by West Nile virus (WNV), an emerging neurotropic flavivirus, inhibition of Ly6Chi monocyte trafficking into the brain by anti-very late antigen (VLA)-4 integrin antibody blockade at the time of first weight loss and leukocyte influx resulted in long-term survival of up to $60 \%$ of infected mice, with subsequent sterilizing immunity. This treatment had no effect on viral titers but appeared to be due to inhibition of Ly6Chi macrophage immigration. Although macrophages isolated from the infected brain induced WNV-specific CD4 ${ }^{+}$T-cell proliferation, $\mathrm{T}$ cells did not directly contribute to pathology, but are likely to be important in viral control, as antibody-mediated T-cell depletion could not reproduce the therapeutic benefit of anti-VLA-4. Instead, 70\% of infiltrating inflammatory monocyte-derived macrophages were found to be making nitric oxide (NO). Furthermore, aminoguanidine-mediated inhibition of induced NO synthase activity in infiltrating macrophages significantly prolonged survival, indicating involvement of $\mathrm{NO}$ in the immunopathology. These data show for the first time the therapeutic effects of temporally targeting pathogenic NO-producing macrophages during neurotropic viral encephalitis.
\end{abstract}

Keywords: Neurotropic virus, Flavivirus, Inflammatory monocytes, West Nile virus encephalitis, Macrophage infiltration, VLA-4, Integrins, Nitric oxide

\section{Findings}

During autoimmune or infectious inflammation of the central nervous system (CNS), inflammatory monocytes migrate into the brain, where they can differentiate into microglia, macrophages, and even dendritic cells [1-3]. The major function of infiltrating inflammatory monocytes is to initiate and amplify the immune response [4-6], but we have recently shown that immigration of these cells into the brain infected with West Nile virus

\footnotetext{
*Correspondence: nickk@pathology.usyd.edu.au

${ }^{1}$ The Discipline of Pathology, School of Medical Sciences Faculty of Medicine, The University of Sydney, Blackburn Building D06, Sydney NSW 2006, Australia

${ }^{3}$ The Bosch Institute, University of Sydney, Sydney, Australia

Full list of author information is available at the end of the article
}

(WNV) contributes directly to the immune pathology of the disease [2]. Inhibition of migration of these cells by anti-chemokine (C-C motif) ligand 2 (CCL2) antibody resulted in a short prolongation of survival in WNV-infected animals [2]. In this report, we extend these findings to show that inflammatory monocytederived macrophages not only migrate into the WNVinfected CNS, utilizing very late antigen (VLA)-4, but play a significant role in driving the immune-mediated pathology, at least in part through sustained production of NO in the symptomatic stages of disease. Importantly, for potential clinical translation, we show that pulsed anti-VLA-4 therapy during acute disease increases the survival of infected animals. 


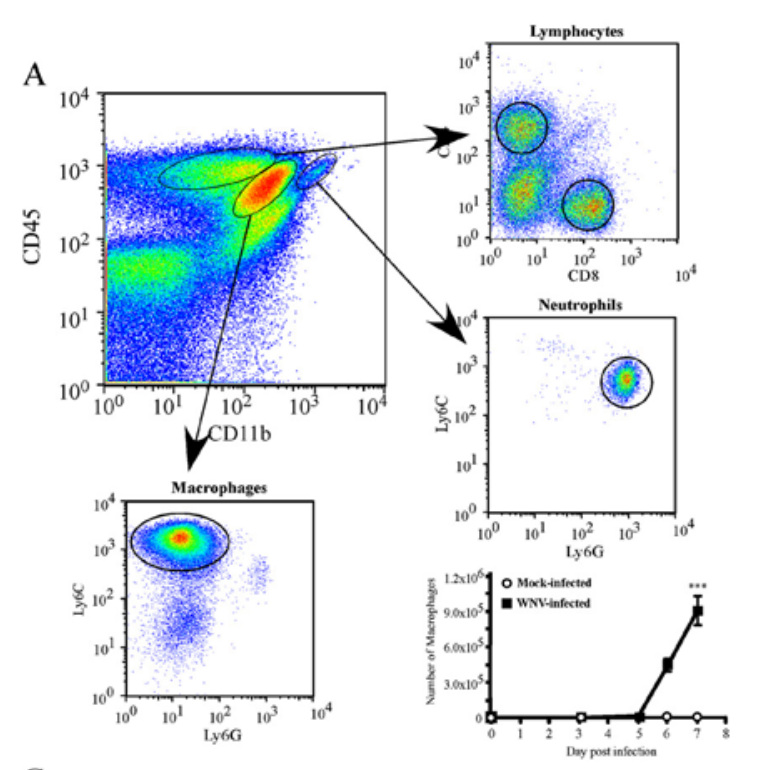

B

C
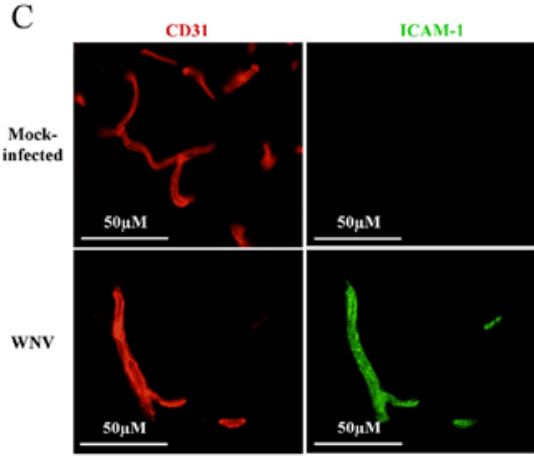

CD31 ICAM-1 DAPI
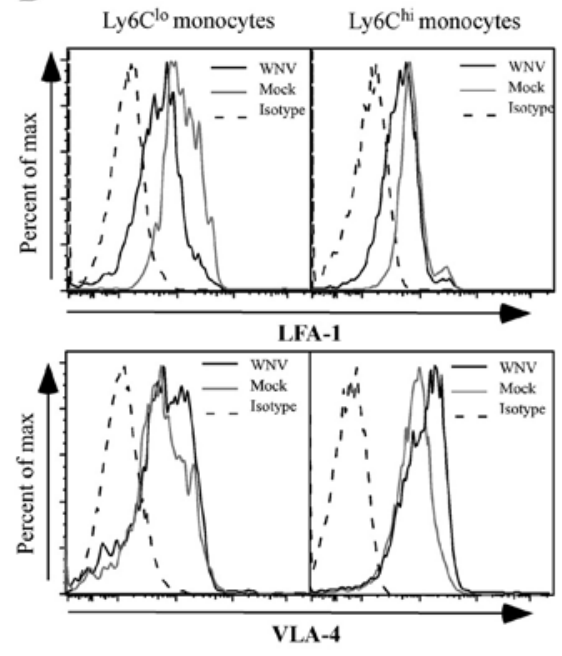

D

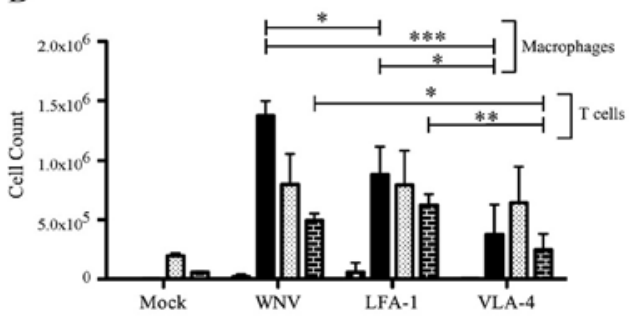

W. Ly6G $^{+}$Neutrophils

\section{CD45 hi Macrophages}

CD45lo/int Microglia

폼 $\mathrm{CD}_{4} 5^{\mathrm{hi}} \mathrm{CD}^{+} \mathrm{T}$ cells

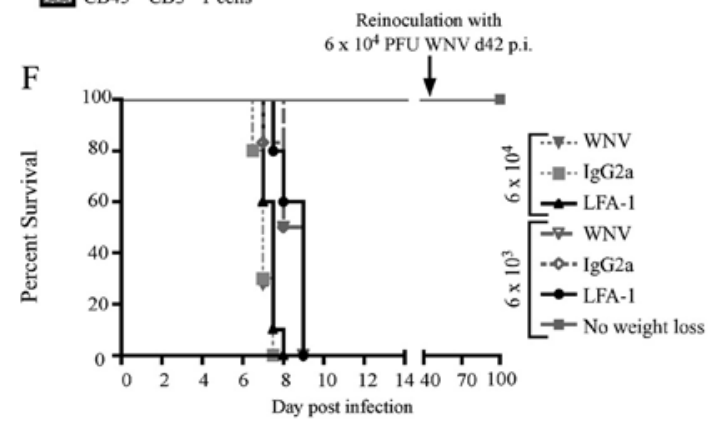

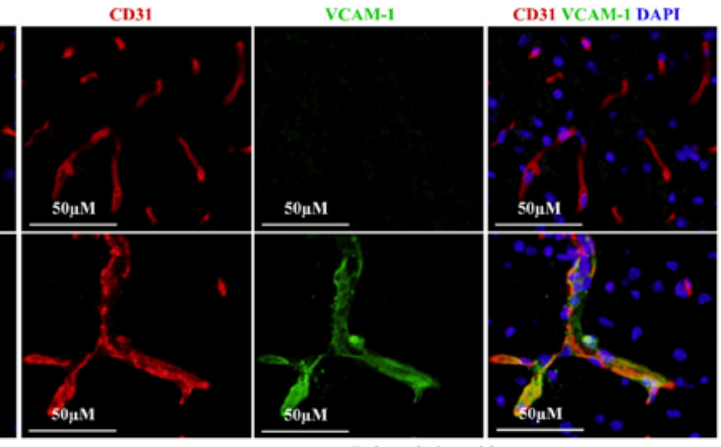

Reinoculation with
$6 \times 10^{4}$ PFU WNV d42 p.i.

E
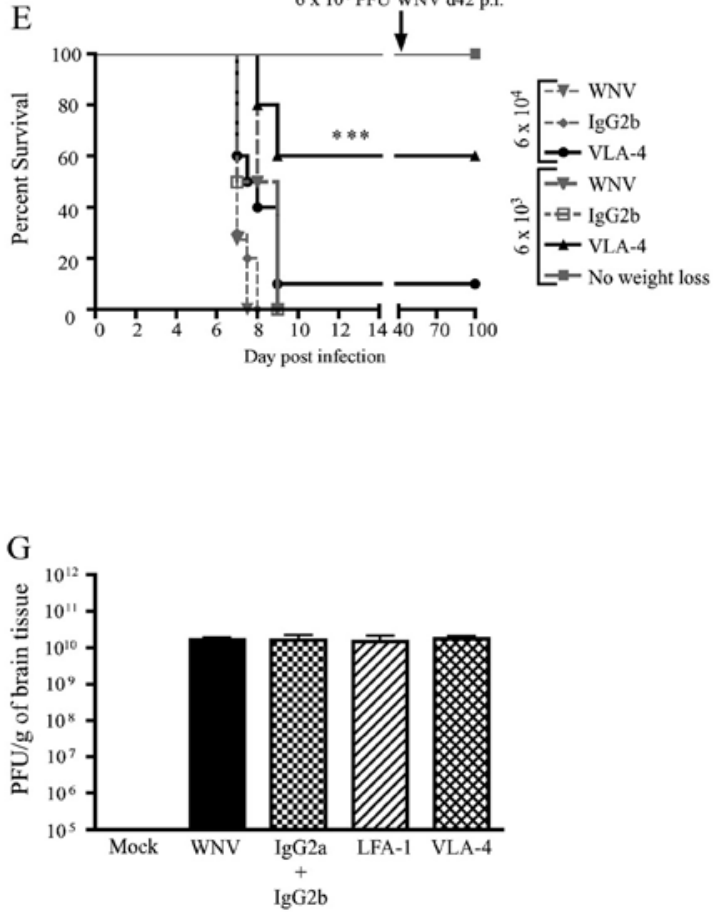

Figure 1 (See legend on next page.) 


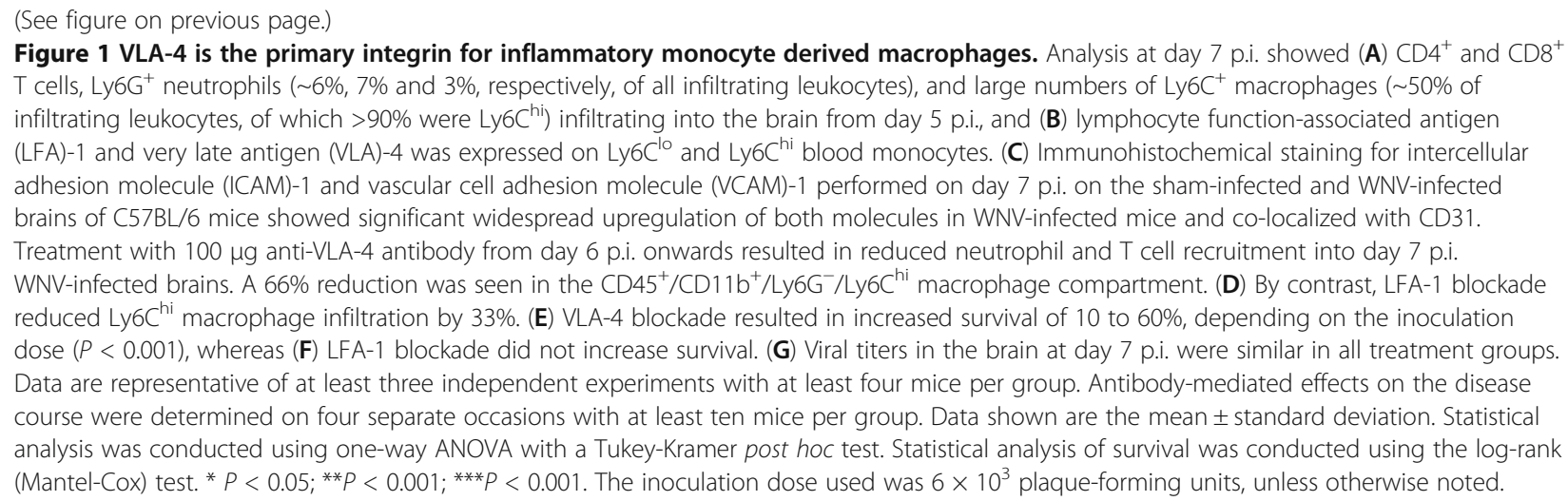

\section{Methods}

\section{Ethics approval}

All procedures were conducted with approval from the animal ethics committee of Sydney University.

\section{Animals}

Female C57BL/6 mice were intranasally inoculated with $6 \times 10^{4}$ or $6 \times 10^{3}$ plaque-forming units (PFU) WNV (Sarafend; Generated as described in 2) or phosphate buffered saline (PBS; Sham control) under anesthesia at 8 weeks old, as previously described [2,7]. For in vivo antibody treatments, mice were injected daily with $100 \mu \mathrm{g}$ anti-CD49d (VLA-4), CD11a (lymphocyte functionassociated antigen-1; LFA-1), CD4, CD8 or isotype control antibodies (Biolegend, San Diego, CA, USA intraperitoneally from day 6 post-infection (p.i.) titrated for maximal effect. For in vivo NO inhibition, mice were injected with $300 \mathrm{mg} / \mathrm{kg}$ aminoguanidine hemisulfate (Sigma) intraperitoneally from day 6 p.i.. For in vivo cathespin labeling, mice were intravenously injected with $2 \mathrm{nmol} / \mathrm{l}$ of a fluorescent agent (ProSense; VisEn Medical, Bedford, MA, USA) on day 6 p.i.. Mice were killed on day 7 p.i. by cardiac perfusion under anesthesia, as previously described [7]. To determine virus titers, plaque assays using homogenized brain on baby hamster kidney cell monolayers were conducted as previously described [7]. For immunohistology, brains were cut into $8 \mu \mathrm{m}$ sections and stained with anti-CD54 (intercellular adhesion molecule-1; ICAM-1), CD106 (vascular cell adhesion molecule 1; VCAM-1), isotype control antibodies (Biolegend), or anti-iNOS (Neomarkers Inc., Fremont, CA, USA), using a previously described immunohistochemical protocol [2]. In situ hybridization for NOS2 was conducted as previously described [7], using a P33-labeled cRNA probe. For flow-cytometry analysis, leukocytes isolated from the brain and blood were incubated with CD16/32 antibody and then labeled with fluorochromeconjugated CD45, CD11b, Ly6C, Ly6G, F4/80, CD3, CD4, CD8, major histocompatibility complex (MHC)-II,
CD80, CD86, CD49d (VLA-4), CD11a (LFA-1) or isotype control antibodies (Biolegend), using a previously described flow-cytometry protocol [2]. For detection of intracellular NO, cells were incubated with $5 \mu \mathrm{mol} / \mathrm{l}$ of a green fluorescent marker that is activated by $\mathrm{NO}$ (4-amino-5-methylamino-2',7'-difluorofluorescein diacetate (DAF-FM); Invitrogen Corp., Carlsbad, CA, USA) for 30 minutes as previously described [8]. Fluorescence was measured, and cell sorting carried out (FACS ARIA; Becton Dickinson, Franklin Lakes, NJ, USA) and analyzed using flow-cytometry software (FlowJo; TreeStar Inc., Ashland, OR, USA). For T-cell proliferation assays, Ly6 $\mathrm{C}^{\text {hi }}$ macrophages, $\mathrm{Ly} 6 \mathrm{C}^{-}$microglia and $\mathrm{CD} 4^{+} \mathrm{T}$ cells were sorted from the brains of colony-stimulating factor 1 receptor (cFMS)enhanced green fluorescent protein (EGFP) chimeras (described previously [2]) and spleens of C57BL/6 mice on day 7 p.i.. cFMS-EGFP is the promoter for CD115 (the macrophage colony-stimulating factor receptor), thus, in these mice, macrophages express EGFP. Assays using 3-(4,5-dimethylthiazol-2-yl)-2,5-diphenyltetrazolium bromide (MTT) assays were conducted in accordance with the manufacturer's instructions (Invitrogen Corp.), with cells plated at the indicated ratios and incubated for a total of 72 hours.

\section{Statistical analysis}

Statistical analysis was conducted using one-way ANOVA with a Tukey-Kramer post hoc test, and statistical analysis of survival was conducted using the log-rank (Mantel-Cox) test. Data shown are means \pm standard deviations. $P<0.05$ was considered significant.

\section{Results and discussion}

\section{Expression of integrins and cellular adhesion molecules}

Previously, we have shown that WNV infection triggers significant limbic-seizure responses that occur immediately preceding death [7]. In addition, acute weight loss correlates with the infiltration of $\mathrm{T}$ cells (14\%) and 


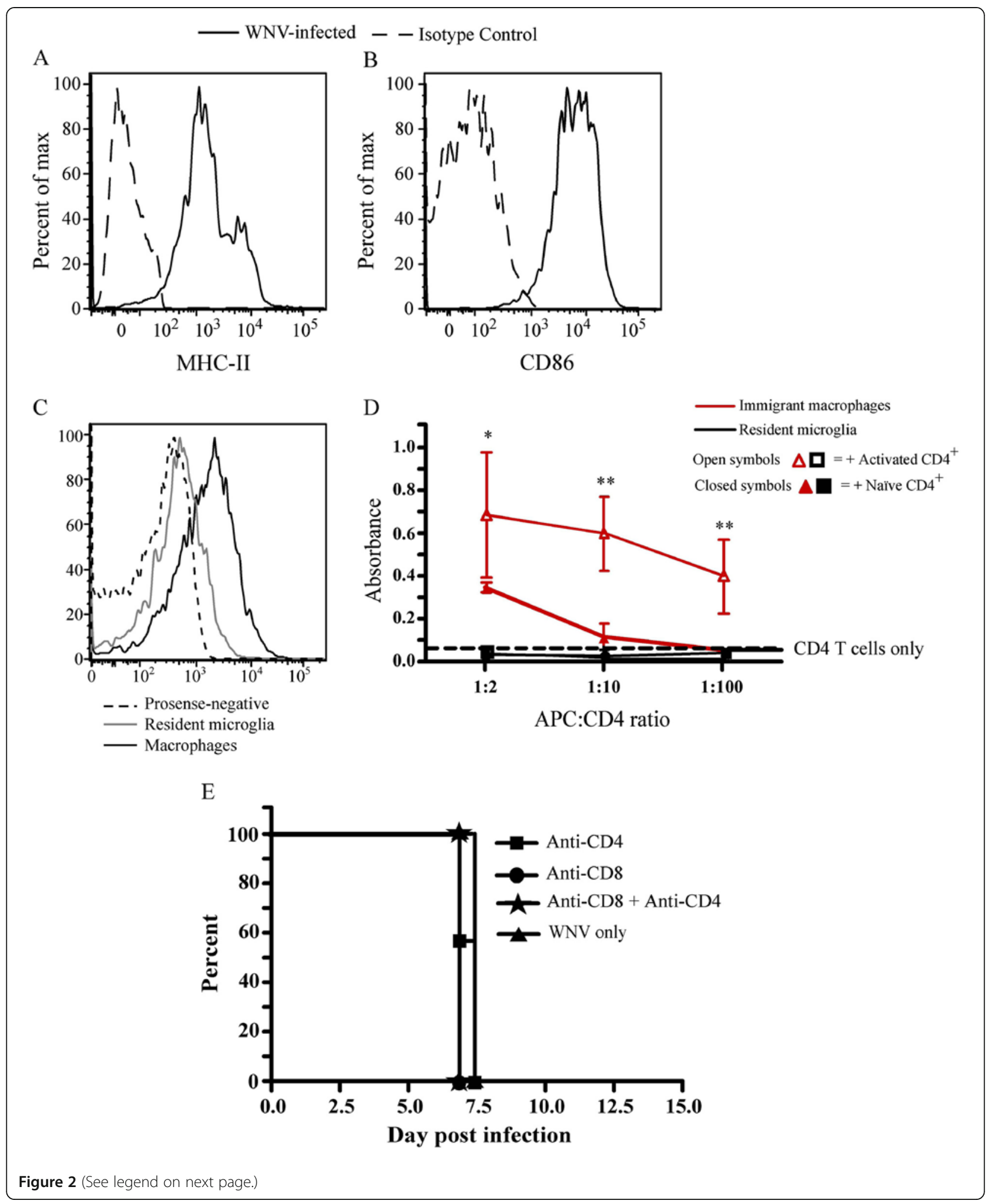

neutrophils (3\%), but the most striking infiltration (by both number and percentage) are Ly6C-expressing inflammatory macrophages ( 50\%) (Figure 1A). This infiltration occurs between days 5 and 7 p.i. (Figure 1A) and without detectable blood-brain barrier disruption in most mice [2]. We could not isolate any from shaminfected mice (Figure 1A) [2]. The mechanism by which inflammatory monocytes enter the brain during WNV 


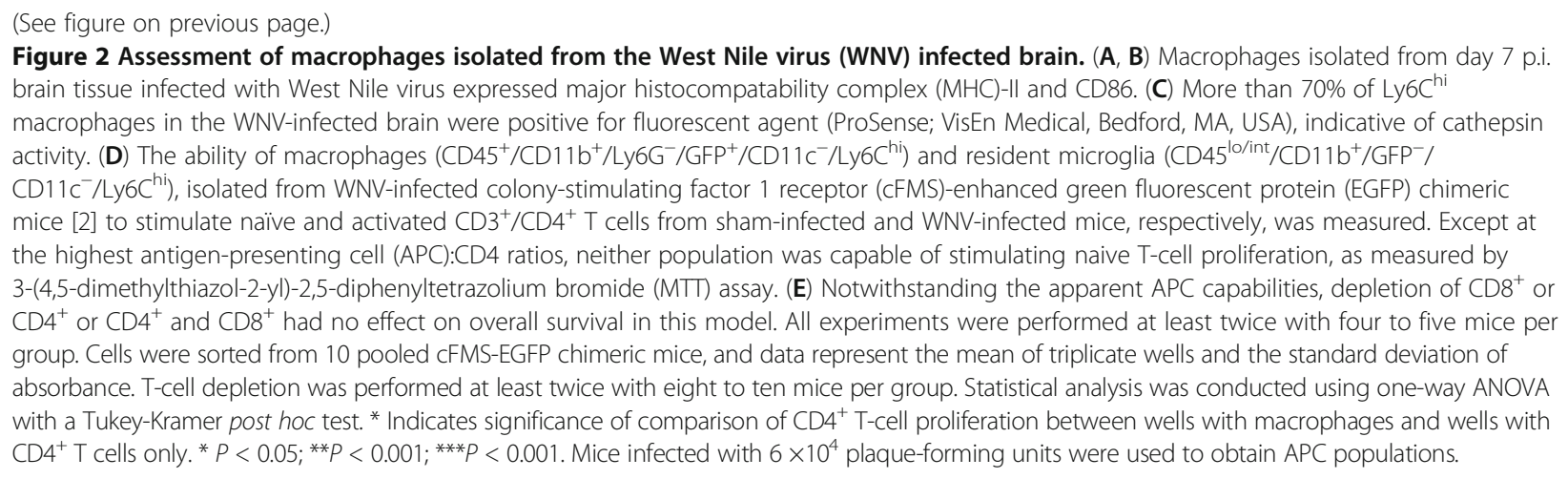

infection has not been addressed. LFA-1 and VLA-4 are integrins important for trans-endothelial migration [9], and were expressed on blood monocytes in WNVinfected and sham-infected mice (Figure 1B). Although a trend toward increased VLA-4 expression on monocytes from WNV-infected mice was seen, it was not significant. Furthermore, expression of the respective ligands for these integrins, ICAM-1 and VCAM-1, was upregulated in the WNV-infected brain. Expression of both ligands was found on platelet endothelial cell adhesion molecule-positive cerebrovascular endothelium (Figure 1C). To investigate the functional role of these integrins, we injected VLA-4-blocking antibody intraperitoneally into WNV-infected mice on day 6 p.i.. Although T-cell numbers decreased, the most dramatic reduction was seen in inflammatory monocyte-derived Ly6C ${ }^{\text {hi }}$ macrophages. This reduction was significantly greater in mice treated with anti-VLA-4 than in those treated with anti-LFA-1 (Figure 1D). VLA-4 antibody blockade resulted in reduced encephalitic symptoms, including a reduction in the incidence of seizures (not shown), culminating in enhanced long-term survival of 10 to $60 \%$ of mice $(P<0.001)$, with subsequent immunity to virus rechallenge, depending on the inoculating dose of virus used (Figure 1E). By contrast, LFA-1 blockade had no effect on the disease course (Figure 1F). Neutralization of LFA-1 or VLA-4 had no effect on viral titers in the brain on day 7 p.i. (Figure 1G), suggesting that survival is not the result of reductions in viral burden or virus cytotoxicity. However, the data support our previous findings suggesting that increased survival is the direct result of decreased inflammatory monocyte trafficking into the brain [2].

The mechanism by which these cells contribute to the pathogenesis of disease is unresolved. To address this, we initially investigated the ability of these cells to process and present antigen to T cells, as CNS macrophages exhibited cathepsin activity and expressed MHCII and CD86 (Figure 2A-C), and we hypothesized that infiltrating macrophages might exert their pathogenic effects indirectly acting as antigen presenting cells (APC), via T-cell stimulation. Using naive and activated $\mathrm{CD}^{+}{ }^{+} \mathrm{T}$ cells, we tested from day 7 p.i. the capacity of immigrant brain macrophages and resident microglia to stimulate $\mathrm{T}$ cell proliferation (Figure 2D). Whereas the control Ly6C (resident) microglia failed to stimulate T-cell proliferation, inflammatory monocyte-derived macrophages were capable of inducing proliferation of activated $\mathrm{T}$ cells, supporting previous studies showing that macrophages can stimulate anti-WNV T-cell responses [10]. It is tempting to speculate from these data that inflammatory monocyte-derived macrophages may cause immunopathology via their influence on T cells [11]; however, deletion of either $\mathrm{CD}^{+}$or $\mathrm{CD}^{+} \mathrm{T}$ cells, or both, did not increase survival time in these mice (Figure 2E). When considered with the reduced number of $\mathrm{T}$ cells seen after anti-VLA-4 treatment, these data potentially argue against a role for $\mathrm{T}$ cells in causing the observed immune pathology in WNV-infected mice. Indeed, previous studies have shown that in concert with neuronal intracellular antiviral defenses, T cells are important for viral clearance [12-14]. Examination of these pathways in VLA-4 treated mice will be needed to clarify these viral eradication mechanisms precisely.

Because NO production during viral infection has been shown to be protective in some instances, and pathogenic in others, we investigated the possible pathogenic role of NO production by macrophages [15-18]. In situ hybridization and immunohistochemistry for inducible NO synthase (NOS)-2 showed significant expression in the WNV-infected brain at day 7 p.i. (Figure 3A-F). Flow cytometry using the NO marker DAF-FM diacetate [8], which becomes fluorescent when it reacts with $\mathrm{NO}$, showed that $72 \%$ of macrophages in the WNV-infected brain expressed $\mathrm{NO}$, compared with only $24 \%$ of resident microglia $\left(\mathrm{CD} 45^{\mathrm{Lo}} / \mathrm{Ly}_{6 \mathrm{C}}{ }^{-}\right)$ (Figure 3G). Furthermore, intraperitoneal administration of aminoguanidine from day 6 p.i. resulted in an increased survival of up to 4 days for infected mice (Figure $3 \mathrm{H}$ ), with the percentage of DAF-FM + macrophages decreasing to less than 12\% (Figure 3G). Furthermore, increased survival 


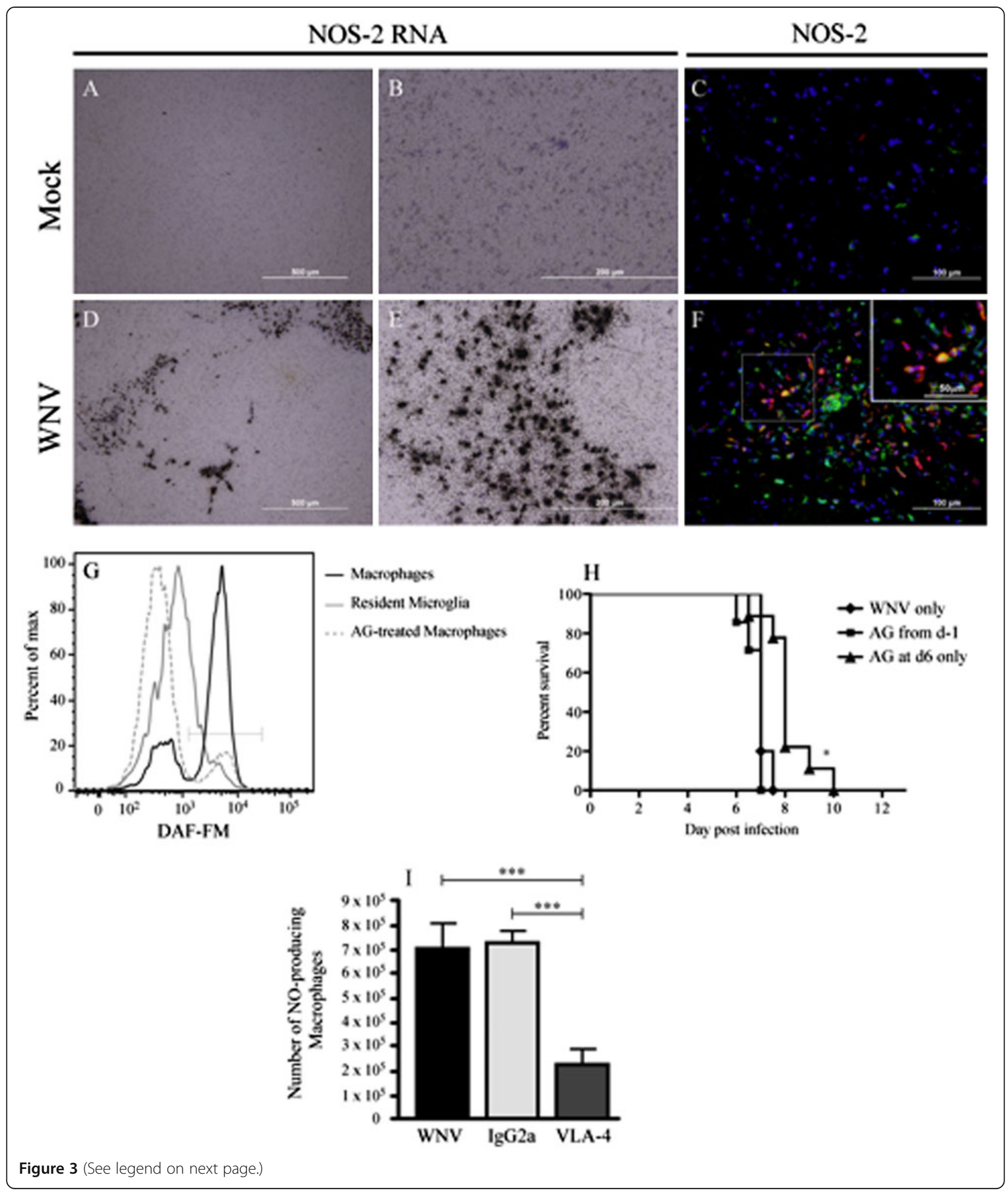

in VLA-4- treated mice correlated with a significant reduction in $\mathrm{NO}^{+}$macrophages in the brain (Figure 3I) at day 7 p.i. Taken together, these data show that inhibition of Ly6 $\mathrm{C}^{\text {hi }}$ monocyte-derived NO, either by reducing the immigration of these cells into the brain, or by inhibiting $\mathrm{NO}$, promotes survival in WNV encephalitis.

Although the production of other pro-inflammatory mediators is also likely to occur via inflammatory 
(See figure on previous page.)

Figure 3 Macrophages produce NO, which is pathogenic during WNV infection. (A-E) Analysis of sections from sham-infected and West Nile virus (WNV)-infected mice at day 7 p.i. showed significant upregulation of nitric oxide synthase (NOS)-2 message in the WNV-infected brains. (C, F) Furthermore, immunohistochemical staining for NOS-2 protein (red) and lectin (green) showed that most cells expressing NOS-2 in the WNV-infected brain parenchyma at day 7 p.i. were lectin-positive. (G) Using the dye 4-amino-5-methylamino-2',7'-difluorofluorescein diacetate (DAF-FM), which, in the presence of NO becomes fluorescent, flow cytometry showed that more than 70\% of macrophages (CD45 hi/CD11b

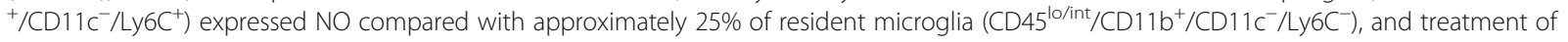
mice with aminoguanidine resulted in a significant reduction in macrophages expressing NO. (H) Inhibition of NO with aminoguanidine did not increase survival when used over the entire infectious period, but it had a demonstrably protective effect given at day 6 p.i. $(P<0.05)$. (I) A significant reduction in DAF-FM-positive macrophages was seen from day 7 p.i. in the brains of WNV-infected mice that had been treated with anti-VLA-4 neutralizing antibodies on day 6 p.i. In situ hybridization was performed on sagittal brain sections from at least six mice per group. DAF-FM data are representative of three experiments with at least three mice per group. Aminoguanidine therapy was performed four times with at least ten mice per group. Values shown are means \pm SD. Statistical analysis was conducted using one-way ANOVA with Tukey-Kramer post hoc test. ${ }^{*} P<0.05$; ${ }^{* *} P<0.001$; ${ }^{* * *} P<0.001$. Statistical analysis of survival was determined using the log-rank (Mantel-Cox) test. ${ }^{*} P<0.05$ was considered significant.

monocyte-derived macrophages, these data provide one potential lethal effector function for pathogenic macrophages that infiltrate into the WNV-infected brain. The production of $\mathrm{NO}$ by macrophages is integral to clearance of many invading pathogens and mediates viral clearance in models of HSV-2, Ectromelia and Vaccinia virus infection [16]. Over-exuberant NO production can be pathogenic, as exemplified by infection by another flavivirus, Murray Valley encephalitis virus, in which experimental inhibition of $\mathrm{NO}$ attenuated disease and prolonged survival [15]. During WNV encephalitis, more than $70 \%$ of the inflammatory monocyte-derived macrophages in the WNV-infected brain produced NO. Importantly, whereas inhibition of NO with aminoguanidine over the entire course of infection had no effect on disease outcome, inhibiting NO on day 6 p.i. resulted in enhanced survival of WNV-infected mice. This apparently paradoxical effect suggests that NO may be important in the early control of WNV infection, whereas later, the sustained production of $\mathrm{NO}$ by large numbers of infiltrating macrophages becomes poorly regulated and thus pathogenic. This is supported by previous macrophage-depletion studies, which show that early prolonged macrophage depletion can result in brain infection in mice infected with a non-encephalogenic WNV strain [19]. It is important to consider that although NOS-2 in situ hybridization studies support a role for macrophages in NO production during WNV encephalitis, NO may also be produced by neurons (neuronal NOS; NOS-1) and endothelium (endothelial NOS; NOS-3). Because arginine is required as a substrate for the production of $\mathrm{NO}$ by all forms of NOS, and aminoguanidine competes with arginine at all these sites, we cannot determine with certainty that the effect we found after aminoguanidine administration is due to the inhibition of NO within macrophages, endothelium, or neurons. In addition, in the brain, NO modulates neurotransmission. Because WNV infection of the brain causes severe seizures, and other studies have implicated $\mathrm{NO}$ in the modulation of neuronal function [7], the ability of NO inhibition at day 6 p.i. to enhance survival of infected mice may also be the result of aminoguanidine interactions that stabilize neurons within the WNVinfected brain. The lack of seizures seen in interferon- $\gamma$ $\left(\mathrm{IFN}-\gamma^{-/-}\right)$mice, as previously described [7], supports this hypothesis. This is because mice deficient in IFN- $\gamma$ have reduced ability to produce $\mathrm{NO}$ and do not develop seizures [7]. However, in IFN- $\gamma^{-1-}$ mice, only the $\mathrm{NO}$ produced via NOS-2 is reduced. Similar survival kinetics were reported with WNV-infected IFN- $\gamma^{-1-}$ mice [7] compared with wildtype mice receiving aminoguanidine from day -1 p.i. throughout the disease course. Together this strongly suggests that the antiviral effects of NOS-2-induced NO are important early during infection and contrasts with its evident pathogenic function, probably via similar mechanisms, late in the disease.

In conclusion, we show here that macrophages derived from Ly6 $\mathrm{C}^{\text {hi }}$ inflammatory monocytes predominantly utilize VLA-4 to enter the CNS. Abrogation of this migration by integrin blockade resulted in long-term survival and immunity in an otherwise lethal model. Finally, these data show the crucial contribution by inflammatory macrophages, within in a narrow, temporally defined window, to the immunopathogenesis of disease. This should inform interventional approaches that can ameliorate immunopathology by targeting a specific myeloid subset (s) in the short term, while enabling virus clearance and host survival.

\section{Abbreviations}

APC: Antigen presenting cell; CNS: Central nervous system; CCL: Chemokine ligand; CD: Cluster of differentiation; CFMS-EGFP: colony-stimulating factor 1 receptor-enhanced green fluorescent protein (Mac Green mouse); DAFFM: 4-amino-5-methylamino-2',7'-diflourofluorescein diacetate;

ICAM: Intercellular adhesion molecule; iNOS: Inducible nitric oxide synthase; LFA-1: Lymphocyte function associated antigen-1; MTT: 3-(4,5-

dimethylthiazol-2-yl)-2,5-diphenyltetrazolium bromide; NO: Nitric oxide; PFU: Plaque-forming units; VCAM: vascular cell adhesion molecule; VLA-4: Very late antigen-4; WNV: West Nile virus.

\section{Competing interests}

The authors have no competing interest to report. 


\section{Authors' contributions}

DG \& NJC designed infection experiments, performed flow cytometry, immunohistochemistry and drafted the manuscript. MT, RT \& CD assisted with experimental design, flow cytomtry and antibody/drug treatments. TMA \& $J R$, optimized and performed immunohistochemistry. MM \& MH designed and completed in-situ hybridizations experiments. ILC designed in-situ primers and assisted with manuscript drafting. All authors read and approved the final manuscript.

\section{Acknowledgements}

We thank Barbara Hernandez for expert histological advice. In addition we thank Ben Roediger and Wolfgang Weninger for the provision of anti-CD31 antibody. This work was funded by NH\&MRC grants 512413 to NJCK and ILC and 1030897 to NJCK and DRG.

\section{Author details}

${ }^{1}$ The Discipline of Pathology, School of Medical Sciences Faculty of Medicine, The University of Sydney, Blackburn Building D06, Sydney NSW 2006, Australia. ${ }^{2}$ The School of Molecular Biosciences, Faculty of Science, University of Sydney, Sydney, Australia. ${ }^{3}$ The Bosch Institute, University of Sydney, Sydney, Australia. ${ }^{4}$ The Centre for Vascular Research, School of Medical Sciences, University of New South Wales, Sydney, Australia.

Received: 12 June 2012 Accepted: 28 September 2012 Published: 30 October 2012

\section{References}

1. D'Agostino PM, Kwak C, Vecchiarelli HA, Toth JG, Miller JM, Masheeb Z, McEwen BS, Bulloch K: Viral-induced encephalitis initiates distinct and functional $\mathrm{CD} 103+\mathrm{CD} 11 \mathrm{~b}+$ brain dendritic cell populations within the olfactory bulb. Proc Natl Acad Sci U S A 2012, 109:6175-6180

2. Getts DR, Terry RL, Getts MT, Muller M, Rana S, Shrestha B, Radford J, Van Rooijen N, Campbell IL, King NJ: Ly6c+ "inflammatory monocytes" are microglial precursors recruited in a pathogenic manner in West Nile virus encephalitis. J Exp Med 2008, 205:2319-2337.

3. King IL, Dickendesher TL, Segal BM: Circulating Ly-6C+myeloid precursors migrate to the CNS and play a pathogenic role during autoimmune demyelinating disease. Blood 2009, 113:3190-3197.

4. Bailey SL, Schreiner B, McMahon EJ, Miller SD: CNS myeloid DCs presenting endogenous myelin peptides 'preferentially' polarize CD4+ $\mathrm{T}(\mathrm{H})-17$ cells in relapsing EAE. Nat Immunol 2007, 8:172-180.

5. Cros J, Cagnard N, Woollard K, Patey N, Zhang SY, Senechal B, Puel A, Biswas SK, Moshous D, Picard C, et al: Human CD14dim monocytes patrol and sense nucleic acids and viruses via TLR7 and TLR8 receptors. Immunity 2010, 33:375-386.

6. Geissmann F, Auffray C, Palframan R, Wirrig C, Ciocca A, Campisi L, Narni-Mancinelli E, Lauvau G: Blood monocytes: distinct subsets, how they relate to dendritic cells, and their possible roles in the regulation of T-cell responses. Immunol Cell Biol 2008, 86:398-408.

7. Getts DR, Matsumoto I, Muller M, Getts MT, Radford J, Shrestha B, Campbell $\mathrm{L}$, King $\mathrm{NJ}$ : Role of IFN-gamma in an experimental murine model of West Nile virus-induced seizures. J Neurochem 2007, 103:1019-1030.

8. Ponomarev ED, Shriver LP, Maresz K, Pedras-Vasconcelos J, Verthelyi D, Dittel BN: GM-CSF production by autoreactive T cells is required for the activation of microglial cells and the onset of experimental autoimmune encephalomyelitis. J Immuno/ 2007, 178:39-48.

9. Ley K, Laudanna C, Cybulsky MI, Nourshargh S: Getting to the site of inflammation: the leukocyte adhesion cascade updated. Nat Rev Immunol 2007, 7:678-689.

10. Kulkarni AB, Mullbacher A, Blanden RV: Functional analysis of macrophages, B cells and splenic dendritic cells as antigen-presenting cells in West Nile virus-specific murine T lymphocyte proliferation. Immunol Cell Biol 1991, 69(Pt 2):71-80

11. McGavern DB, Truong P: Rebuilding an immune-mediated central nervous system disease: weighing the pathogenicity of antigen-specific versus bystander T cells. J Immunol 2004, 173:4779-4790.

12. Samuel MA, Whitby K, Keller BC, Marri A, Barchet W, Williams BR, Silverman $\mathrm{RH}$, Gale M Jr, Diamond MS: PKR and RNase L contribute to protection against lethal West Nile virus infection by controlling early viral spread in the periphery and replication in neurons. J Virol 2006, 80:7009-7019.
13. Shrestha B, Diamond MS: Role of CD8+ T cells in control of West Nile virus infection. J Virol 2004, 78:8312-8321.

14. Wang $Y$, Lobigs $M$, Lee $E$, Mullbacher A: CD8+ T cells mediate recovery and immunopathology in West Nile virus encephalitis. J Virol 2003, 77:13323-13334.

15. Andrews DM, Matthews VB, Sammels LM, Carrello AC, MCMinn PC: The severity of murray valley encephalitis in mice is linked to neutrophil infiltration and inducible nitric oxide synthase activity in the central nervous system. J Virol 1999, 73:8781-8790.

16. Karupiah G, Xie QW, Buller RM, Nathan C, Duarte C, MacMicking JD: Inhibition of viral replication by interferon-gamma-induced nitric oxide synthase. Science 1993, 261:1445-1448.

17. Noda S, Tanaka K, Sawamura S, Sasaki M, Matsumoto T, Mikami K, Aiba Y, Hasegawa H, Kawabe N, Koga Y: Role of nitric oxide synthase type 2 in acute infection with murine cytomegalovirus. J Immunol 2001, 166:3533-3541.

18. Presti RM, Popkin DL, Connick M, Paetzold S, Virgin HW: Novel cell typespecific antiviral mechanism of interferon gamma action in macrophages. J Exp Med 2001, 193:483-496.

19. Ben-Nathan D, Huitinga I, Lustig S, van Rooijen N, Kobiler D: West Nile virus neuroinvasion and encephalitis induced by macrophage depletion in mice. Arch Virol 1996, 141:459-469.

\section{doi:10.1186/1742-2094-9-246}

Cite this article as: Getts et al:: Targeted blockade in lethal West Nile virus encephalitis indicates a crucial role for very late antigen (VLA)-4dependent recruitment of nitric oxide-producing macrophages. Journal of Neuroinflammation 2012 9:246.

\section{Submit your next manuscript to BioMed Central and take full advantage of:}

- Convenient online submission

- Thorough peer review

- No space constraints or color figure charges

- Immediate publication on acceptance

- Inclusion in PubMed, CAS, Scopus and Google Scholar

- Research which is freely available for redistribution 